\title{
THE TRAINER PROJECT: MATCHING TRAINING CURRICULA TO DRIVERS REAL NEEDS USING MULTIMEDIA TOOLS
}

\author{
Herregods, $D^{1}$., Nowé $\mathrm{H}^{1}$., Bekiaris, $\mathrm{A}^{2}$., Baten, $\mathrm{G}^{3}$., Knoll, $\mathrm{C}^{4}$. \\ ${ }^{1} \mathrm{DKH}$, Driving Know-How Consulting, Belgium \\ ${ }^{2}$ AUTH, Aristotle University of Thessaloniki, Greece \\ ${ }^{3}$ CARA, Belgian Road Safety Institute,Belgium \\ ${ }^{4}$ IAT, University of Stuttgart, Germany \\ Daniel Herregods - Hervé Nowe \\ DKH - Pole ProMotions sprl/bvba \\ Driving Know-How Consulting \\ Leuvensesteenweg, 312/1 \\ 3070 KORTENBERG (BELGIUM) \\ email: h.nowe@driving-know-how.com
}

\begin{abstract}
One of the more important issues in road insecurity is that drivers are not enough conscious of all the dynamics involved while driving a vehicle. Historically, driver training has focused on vehicle control skills and traffic rules without reaching far enough in the efforts to provide risk awareness and other higher order skills. The European Union supported "TRAINER" project addresses this problem with the development of a cost-effective Pan-European driver training methodology based on realistic, interactive, off-road tools: a new interactive multimedia training tool, a low cost stationary and a mean cost semi-dynamic driving simulator.

This paper describes the interactive multimedia tool requirements and scenarios design to support driver training and assessment in strategic and manoeuvring tasks. The more than 100 different scenarios developed allows training and assessment of higher cognitive skills and familiarisation of novice drivers with the basic principles of driving: safety belt use, alcohol driving influence, gap acceptance, headway tailgating, peripheral view, yielding, lane changing, turning, unforeseen events, hazard perception, overtaking manoeuvres, visual cues, parked car, intersection turning, pedestrians and children and so on.
\end{abstract}

After verification of the methodology and assessment of the effect on risk awareness enhancement of learners drivers through tests with 30 novice drivers (and an equal control group) in 4 European countries, the TRAINER tools will be integrated into a common European driver education and assessment methodology, that will also contribute towards safe integration of novice drivers into the traffic environment. 